\title{
Renal Ptosis: Case Literature Review
}

Yacouba Garba Karim *1,2, Mar Ndeye Bigue ${ }^{3}$, Seck Issa Dior ${ }^{1}$, Niane Sokhna Astou Gawane Thiam ${ }^{1}$, Tireira Daouda Harouna ${ }^{1}$, Wade Racky ${ }^{1}$, Gaye Magaye ${ }^{1}$, Ndiaye Ainina ${ }^{1}$, Ndoye Jean Marc ${ }^{1}$, Diop Mamadou ${ }^{1}$, Ndiaye Abdoulaye ${ }^{1}$, Ndiaye Assane $^{2}$.

${ }^{* 1}$ Laboratoire d'anatomie et d'organogenèse, Université Cheikh Anta Diop (UCAD), Dakar, Sénégal.

${ }^{2}$ Laboratoire d'anatomie et d'organogenèse, Université Assane Seck Ziguinchor (UASZ), Ziguinchor, Sénégal.

${ }^{3}$ Laboratoire d'anatomie et d'organogenèse, Université Iba Der Thiam (UIT), Thiès, Sénégal.

\section{ABSTRACT}

We report a fortuitously discovered case of renal ptosis in a 9-year-old girl. We take this opportunity to review literature on the embryological, clinical and therapeutic aspects of this malformation, which is the most common renal ectopia diagnosed in sub-Saharan Africa.

KEY WORDS: Kidney, Ptosis, Nephroptosis.

Corresponding Author: Karim Yacouba Garba, Laboratoire d'anatomie et d'organogenèse, Université Cheikh Anta Diop (UCAD), Dakar, Sénégal. Tel : 221777980527

E-Mail: ygkarim243@gmail.com

Access this Article online Quick Response code

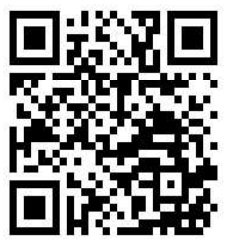

DOI: $10.16965 /$ ijar.2021.121

\begin{tabular}{l} 
\\
\hline Rece \\
\hline Revis
\end{tabular}

Journal Information
International Journal of Anatomy and Research

ISSN (E) 2321-4287 | ISSN (P) 2321-8967

https://www.ijmhr.org/ijar.htm

DOI-Prefix: https://dx.doi.org/10.16965/ijar

Article Information

\section{INTRODUCTION}

Renal ptosis (or nephroposis) results in the downward movement of the kidney associated with abnormal mobility due to the relaxation of its fixity means. It corresponds to a descent of the kidney, from its normal position, of at least $5 \mathrm{~cm}$ or 2 vertebral bodies [1]. Renal ptosis is the most common of renal ectopies, its incidence is $14 \%$ [4].

Clinically, renal ptosis is often incidental; otherwise it is revealed by a pain of the right iliac fossa [3]. In case of associated pathology such as pyelo-ureteral junction syndrome, infection or giant hydronephrosis, surgical treatment should be discussed (pyeloplasty, nephrectomy, kidney transplant) [3].
Accepted: 17 Apr 2021

Published (O): 11 May 2021

Published (P): 05 Jun 2021

\section{(cc) Ev-No-Bi}

We report a case of renal ptosis associated with pyelo-ureteral junction syndrome discovered in a young girl and conduct a literature review on embryological, epidemiological, clinical and therapeutic levels.

\section{OBSERVATIONS}

The observation concerned a 9-year-old female subject who consulted at the Albert Royer Children's Hospital (HEAR) in Fann for acute, intense, intermittent abdominal pain, sitting at the level of the right iliac fossa radiating towards the thigh without signs of accompaniment.

Antecedents included adenoidectomy in 2008 and tonsillectomy in 2009. The clinical 
examination found a soft, painless abdomen without palpable mass, without mattity of the flanks or cries of the umbilicus. The rectal touch was painless. The CBC, ECBU, bladder were normal and the CRP was $96 \mathrm{mg} / \mathrm{l}$.

The abdominal-pelvic ultrasound objectified right renal ptosis associated with a discrete pyelic dilatation without obvious obstacle.

The abdominal pelvic computed tomography confirmed a polar pyelo-calicielle dilatation secondary to a pyelo-ureteral junction syndrome on a floating right kidney, hypotrophic with $7.5 \mathrm{~cm}$ of long axis (Figure 1 and 2).

The indication of pyeloplasty was set but before the refusal of the parents, symptomatic treatment was instituted. In evolution, there were more and more diffuse painful recurrences, simulating a surgical abdomen.

Fig. 1: Left anterior-lateral view showing the thoracicabdominal-pelvic skeleton with the kidneys.

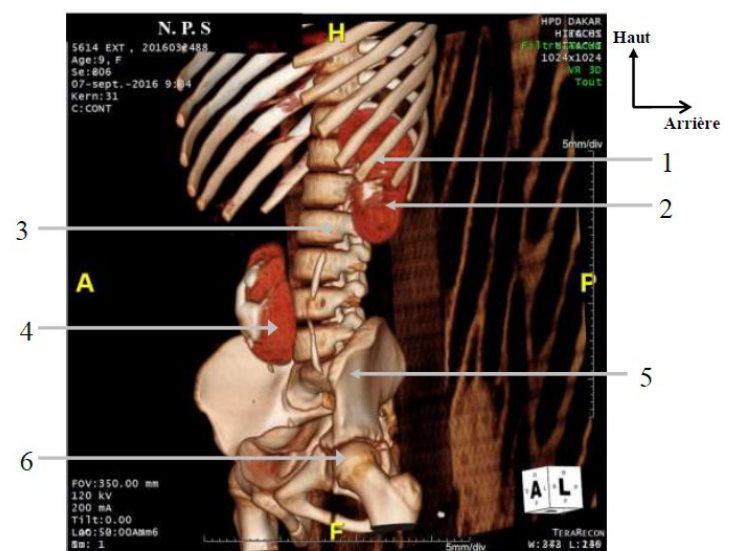

1- K10 2- Left kidney 3- 2nd Lumbar Vertebra

4- Right kidney ptosis 5- Left Coxal Bone

6- Left femoral head

Fig. 2: Abdominal cross-section in Th12 without contrast iniection.

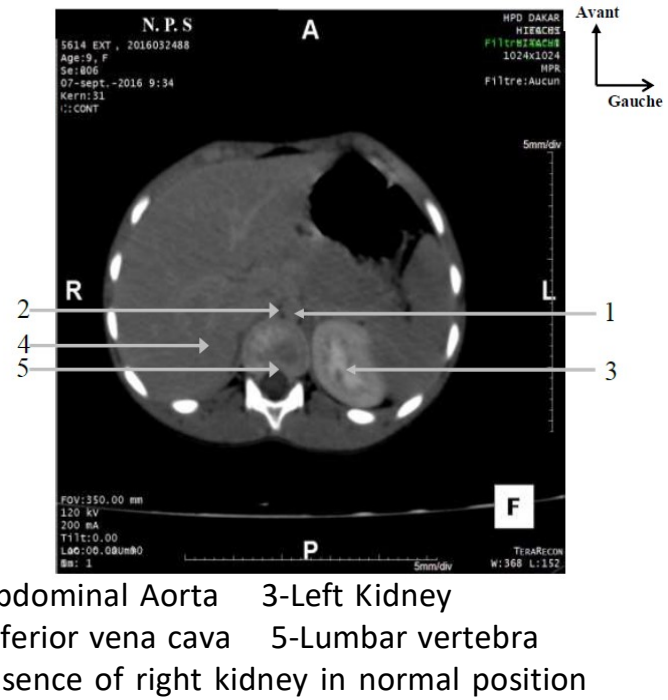

\section{DISCUSSION}

In Senegal, the incidence of renal ptosis is not known. Dieulafoy's work shows an incidence of $14 \%$ ectopia [4], nephroposis affects $20 \%$ of women with a right predominance [2]; this is confirmed by Winfield [12]. Bilateral involvement is rare [4].

Embryologically, after the 8th week of intrauterine development, the mesoderm begins to disappear. The permanent kidney (mesonephritic) is in the pelvis, at the caudal part of the intermediate mesoderm. Then it goes up to the dorsal wall of the abdomen. The renal hilum is oriented forward. During their ascents, each of the 2 kidneys rotates $90^{\circ}$ so that the hilum and the vessels of the hilum become medial as in adults. The kidneys remain in the retroperitoneal space throughout the process [6].

During this ascent, the kidneys cross the arterial fork of the umbilical arteries. In case of migration defect, the kidney remains in the pelvis in the vicinity of the primitive iliac artery: it is the pelvic ectopia of the kidney.

Ptosis is more common in adults with an average age of 33 years [11].

Anatomically, there are 3 different grades of nephroposis:

Grade I: the kidney descends laterally along the outer edge of the psoas muscle;

Grade II: the kidney has a more accentuated descent and rests on the psoas muscle accompanied by a tilt towards the anterior;

Grade III: The kidney makes a full tilt in the pelvis.

Grade I ptosis is not pathological. Grades II and III can be used and cause malfunction [7]. Our patient has grade II ptosis with a medial kidney at the height of the $3 \mathrm{rd}, 4^{\text {th }}$ and 5 th lumbar vertebrae.

According to Sebe [10], ptosis will allow vascularization of the kidney significantly because whatever the number of arteries, there is a branch coming from the aortic bifurcation. When the kidney is in the pelvic position, the frequency of multiple arteries is approximately $50 \%[10,11]$. 
Clinically, this malformation is often incidentally discovered by medical imaging. It can also be revealed by abdominal pain [1]. It varies according to its seat, its nature and its intensity. This typically localized pain in the right iliac fossa may radiate to the sides, to the hypochondrias see in the thighs making walking difficult [1]; This is the case with our patient. In the face of this dubious form, peritonitis [9] and strangulation syndrome [4] must be eliminated.

In our observation, right renal ptosis is associated with pyelo-ureteral junction syndrome. However, the literature reports other associations of urinary tract infection, pyelo-calicielle dilatation, giant hydronephrosis, urinary lithiasis, and high blood pressure. Skeletal involvement in a poly malformative syndrome and tumours may be circumstances of discovery of renal ptosis $[8,13]$.

Abdominal-pelvic ultrasound is the first-line examination to diagnose renal ptosis associated with pyelo-urethral junction syndrome. The uro-scanner (Uro-CT) is used to locate the seat of the ptose kidney [1]; Injected renal angio-scanner [3] allows vascular mapping; and furosemide-tested 99mTc-DTPA renal scintigraphy to assess the permeability of the excretory urinary tract of renal ptosis [5].

On the etiological level, the contusions of the lumbar region, the relaxation of the abdominal walls in women following repeated pregnancies as well as the rapid disappearance of cellular tissue kidney in obese individuals may cause the discovery of nephroposis [4,9].

The indication of a surgical procedure is placed before a urinary tract infection or hydronephrosis. Surgery should take into account a first step to avoid the difficulties associated with vascular abnormalities [3]. Thus, Boujnah et al. [3] propose the extra peritoneal ilio-pelvic pathway for pyelo-ureteral junction syndrome and simple lithiasis, and the trans-peritoneal pathway in cases of condition requiring renal pedicle control. In any case, surgery will be reserved for complicated forms.

\section{CONCLUSION}

Renal ptosis is the most common and usual renal ectopia. It is manifested by abdominal pain and is most often observed in women. Its discovery is most often fortuitous during medical imaging such as ultrasound which makes it possible to make the diagnosis and computed tomography to detect the associated abnormalities. Therapeutic abstention is the rule in the absence of complications and its monitoring is done with periodic ultrasounds.

\section{ACKNOWLEDGEMENTS}

The authors wish to thank Professor Assane NDIAYE for the follow-up and encouragement during the redaction of this document.

\section{Conflicts of Interests: None}

\section{REFERENCES}

[1]. Benchekroun A, Kasmaoui E H, Jira H, Iken A, Nouini $Y$, Benslimane $L$, et al. The pathological pelvic kidney. It's about 11 cases. Ann Urol, 2002; 36(4): 231-5.

[2]. Boccardo G , Ettari G , De Prisco O , Donato G , Maurino D. Renal ptosis: nephrologic consequences of an organ malposition. Minerva Urol Nefrol, 1994; 46(4):195-204.

[3]. Boujnah H, Abid I, Moalla N, Zmerli S. It's the pelvic kidney. About fifty cases. Ann Urol 1989;23:11-6.

[4]. CDIGITAL.DGB. U ANL.MX (INTERNET) MOBILE KIDNEY: Kidney displacement, acquired renal ectopia, floating kidney, dislocation of kidneys: 880-885 Retrieved March 02, 2017. Available from: http://cdigital.dgb.uanl.mx/la/1030000182/ 1030000182_76.pdf

[5]. Ghfir I, Ben Rais N. Iliac renal ectopia scanned with 99mTc-DTPA and 99mTc-DMSA. About a case Nuclear Medicine, 2008; 32: 559-63.

[6]. Larry RC, Netter H F. Netter's Human Embryology Atlas. De boeck, March 2015, 1st edition; 292p

[7]. Lason G, Peeters L. The kidneys and adrenal glands. Brussels: e-book, 2000. 101p; 36-40.

[8]. Ndiaye Aï, Ndiaye As, Fall B, Mane L, Ndoye JM, Ndiaye A, Dia A. Crossed renal ectopia: About a case. JAMO, 2008; 2: 23-4.

[9]. O'followell L. Le corset, Paris: Maloine, 1908, 312p.

[10]. Sebe P, Chemla E, Varkarakis J, Latremouille C. Anatomical variations of pelvic kidney vascularization: about a case and literature review. orpho, 2004; 280(80): 24-6.

[11]. Sidibe S, Kané M, Keita A, Traoré I. Atypical forms of Mayer-Rokitansky-Ruster-Hauser syndrome: Role of ultrasound. J Radiol, 1999; 80: 948-50.

[12]. Winfield H. Nephroptosis. The 5-Minute Urology Consult, 2000;1:368-9.

[13]. Yassine R. Giant hydronephrosis on pelvic ectopic kidney revealed by occlusive syndrome: Rare cases. A J Urol, 2014: 20: 211-4. 